\title{
Kurrgefalste Anleitung
}

\author{
zur

\section{qualitativen chemischen Analyse.}

Zusanmengestelit

voul

Carre Pistor

Assistent um chem. Univ.-Laboratorium zu Giessen.

Giefsen.

Druck von Wilhelm Keller.

1883. 